\title{
Cardiac resynchronization therapy in chronic heart failure: Effect on right ventricular function
}

\author{
Dominik C. Benz, MD, a and Aju P. Pazhenkottil, MD, FESC \\ a Cardiac Imaging, Department of Nuclear Medicine, University Hospital Zurich, Zurich, \\ Switzerland
}

Received May 31, 2017; accepted May 31, 2017

doi: 10.1007/s12350-017-0953-5

\section{See related article, pp. 123-132}

It is well known that patients with left ventricular (LV) dysfunction have poor survival. Only a few decades ago, the probability of dying within 5 years from the onset of congestive heart failure was more than $40 \% .^{1}$ But recent years have witnessed tremendous therapeutic advances with the introduction of angiotensin-converting enzyme inhibitors, beta-blockers, angiotensin receptor blockers, aldosterone antagonists, and, recently, with angiotensin-neprilysin inhibitors so that this number could be substantially decreased. However, in some patients with chronic heart failure, the disease process not only impairs cardiac contractility but also causes a delay in the onset of right ventricular (RV) or LV systole by affecting the conduction pathways. Such dyssynchrony-as visualized on the electrocardiogram by a QRS duration of $120 \mathrm{msec}$ or longermay further depress the capacity of the heart to eject blood. Therefore, a device to coordinate RV and LV contraction has been developed. More than ten years ago, it has been demonstrated that cardiac resynchronization therapy (CRT) improves symptoms and quality of life as well as reduces complications and risk of death. $^{2,3}$ Therefore, current guidelines recommend CRT in symptomatic patients if $\mathrm{LV}$ ejection fraction (LVEF) is $\leq 35 \%$ and QRS duration is $\geq 130 \mathrm{msec}$ (with left bundle branch block morphology). ${ }^{4}$ However, mechanical dyssynchrony may also occur in patients with a

Reprint requests: Aju P. Pazhenkottil, MD, FESC, Cardiac Imaging, Department of Cardiology and Nuclear Medicine, University Hospital Zurich, Ramistrasse 100, CH-8091, Zurich, Switzerland; aju.pazhenkottil@usz.ch

J Nucl Cardiol 2019;26:133-5.

$1071-3581 / \$ 34.00$

Copyright (C) 2017 American Society of Nuclear Cardiology. narrow QRS complex. While single-center studies suggested that patients with echocardiographic evidence of mechanical dyssynchrony may benefit from CRT, 5,6 these findings could not be confirmed by a large randomized trial $^{7}$ and, as a consequence, indications for CRT have not been expanded. Hence, improving the selection of candidates for CRT by imaging-derived LV dyssynchrony parameters has not met the clinical expectations yet. Nonetheless, studies are under way to better establish the role of imaging in predicting CRT response-like for example EuroCRT, a large European multicenter prospective observational study. ${ }^{8}$

The role of RV dysfunction in the response to CRT, on the contrary, is even less clear. Similar to LV dysfunction, RV dysfunction is a marker of poor prognosis in heart failure patients. Moreover, impaired baseline RV function was found to be associated with worse survival after CRT compared to patients with normal RV function. ${ }^{9}$ Interestingly, RV dysfunction was associated with poor response to CRT, i.e., poor LV reverse remodeling after CRT, ${ }^{10}$ suggesting that RV function might assist in identifying patients who respond more favorably to CRT. However, these data have not been supported by studies from randomized trials. A subanalysis of the CARE-HF study showed that although RV dysfunction is a relevant predictor of death among patients with and without CRT, the prognostic benefit of CRT was not diminished in patients with RV dysfunction. ${ }^{11}$ In addition, a recent meta-analysis concluded that echocardiographic parameters of RV function do not predict response to CRT as assessed by change in LVEF. ${ }^{12}$ However, RV function was evaluated in all of these studies by echocardiography which is challenging due to the complex anatomy and geometry. Since cardiac magnetic resonance cannot be performed in most CRT patients, radionuclide angiography could be an optimal alternative to overcome these issues. In fact, phase analysis from nuclear myocardial perfusion imaging has recently gained wide interest as a potential alternative to assess dyssynchrony. ${ }^{13,14}$ 
In the current issue of the Journal, Valzania et al. investigated in a prospective manner the effects of CRT on RV function and plasma NT-pro-BNP levels in 36 consecutive patients with non-ischemic dilated cardiomyopathy at baseline with CRT switched off, 10 minutes after CRT activation and 3 months later. In contrast to previous studies, RV function and inter- as well as intraventricular dyssynchrony were assessed by $\mathrm{Tc}^{99 \mathrm{~m}}$ radionuclide angiography. Patients were stratified according to $\mathrm{RV}$ ejection fraction (RVEF), resulting in 14 patients $(39 \%)$ with impaired RVEF $(\leq 35 \%)$ and 22 patients $(61 \%)$ with preserved RVEF during spontaneous rhythm at baseline. While among patients with impaired RVEF RV dyssynchrony was higher at baseline, LVEF, LV dyssynchrony and interventricular dyssynchrony were similar in the two groups. Conversely, LVEF improved only in patients with preserved RV function. Three months later, LVEF improved in both groups to a similar extent-with a lower, albeit not significant, rate of CRT responders among patients with an impaired RVEF vs patients with preserved RVEF (50\% vs. $64 \%, P=$ ns). Regarding RV function, RVEF and RV dyssynchrony improved among patients with an impaired RVEF, while in patients with preserved RVEF only RV dyssynchrony improved with no changes in RVEF. NT-pro-BNP levels were comparable at baseline in patients with impaired and preserved RV function, and decreased in both groups to a similar extent. Moreover, significant correlations were found between the decrease in NT-pro-BNP and the improvement in RVEF, RV dyssynchrony, LVEF, and LV dyssynchrony.

The authors should be congratulated for this elegantly and properly performed study showing the feasibility and robustness of radionuclide angiography that occasionally falls into oblivion. The study highlights the underestimated potential of nuclear cardiology to identify CRT responders by assessing $\mathrm{LV}$ and RV function in a population where cardiac magnetic resonance imaging is often contraindicated. The present findings extend previous observations from echocardiographic studies ${ }^{15,16}$ indicating that RV dyssynchrony improves independent of RVEF at baseline. However, the overall increase of RVEF after CRT is the result of improved RVEF in patients with impaired RVEF at baseline. Additionally, the study revealed that LVEF is improved after CRT independent of baseline RVEF implying that RV dysfunction is not a reason to exclude the prescription of CRT in these patients. Nevertheless, the CRT responder rate tended to be lower in the group with impaired vs. preserved baseline RV function, but no statistical significance has been reached. It might be argued that the study has failed to reach a significant difference due to the lack of power. However, since the conclusion of the present study matches with the results of a larger prospective study and a meta-analysis, ${ }^{11,12}$ it seems unlikely that an increase of sample size might have altered the results. While outcome was beyond the scope of the present study, it would have been interesting to see whether improvement in RVEF resulted in improved survival.

Ultimately, the findings of the current study add an important piece to the growing evidence that baseline RV function does not define CRT response as assessed by a change in LVEF. Moreover, it makes a strong case for radionuclide angiography in the estimation of $\mathrm{RV}$ function which should be taken into consideration when further exploring the role of imaging-derived parameters to predict the response to CRT.

\section{Disclosure}

The University Hospital Zurich holds a research agreement with GE Healthcare.

\section{References}

1. McKee PA, Castelli WP, McNamara PM, Kannel WB. The natural history of congestive heart failure: The Framingham study. N Engl J Med 1971;285:1441-6.

2. Abraham WT, Fisher WG, Smith AL, Delurgio DB, Leon AR, Loh $\mathrm{E}$, et al. Cardiac resynchronization in chronic heart failure. N Engl J Med 2002;346:1845-53.

3. Cleland JG, Daubert JC, Erdmann E, Freemantle N, Gras D, Kappenberger L, et al. The effect of cardiac resynchronization on morbidity and mortality in heart failure. $\mathrm{N}$ Engl $\mathrm{J}$ Med 2005;352:1539-49.

4. Ponikowski P, Voors AA, Anker SD, Bueno H, Cleland JG, Coats AJ, et al. 2016 ESC Guidelines for the diagnosis and treatment of acute and chronic heart failure: The Task Force for the diagnosis and treatment of acute and chronic heart failure of the European Society of Cardiology (ESC) Developed with the special contribution of the Heart Failure Association (HFA) of the ESC. Eur Heart J 2016;37:2129-200.

5. Bleeker GB, Holman ER, Steendijk P, Boersma E, van der Wall EE, Schalij MJ, et al. Cardiac resynchronization therapy in patients with a narrow QRS complex. J Am Coll Cardiol 2006;48:2243-50.

6. Yu CM, Chan YS, Zhang Q, Yip GW, Chan CK, Kum LC, et al. Benefits of cardiac resynchronization therapy for heart failure patients with narrow QRS complexes and coexisting systolic asynchrony by echocardiography. J Am Coll Cardiol 2006;48: 2251-7.

7. Ruschitzka F, Abraham WT, Singh JP, Bax JJ, Borer JS, Brugada $\mathrm{J}$, et al. Cardiac-resynchronization therapy in heart failure with a narrow QRS complex. N Engl J Med 2013;369:1395-405.

8. Donal E, Delgado V, Magne J, Bucciarelli-Ducci C, Leclercq C, Cosyns B, et al. Rational and design of EuroCRT: An international observational study on multi-modality imaging and cardiac resynchronization therapy. Eur Heart J Cardiovasc Imaging 2017. doi:10.1093/ehjci/jex021.

9. Leong DP, Höke U, Delgado V, Auger D, Witkowski T, Thijssen $\mathrm{J}$, et al. Right ventricular function and survival following cardiac resynchronisation therapy. Heart 2013;99:722-8. 
10. Scuteri L, Rordorf R, Marsan NA, Landolina M, Magrini G, Klersy $\mathrm{C}$, et al. Relevance of echocardiographic evaluation of right ventricular function in patients undergoing cardiac resynchronization therapy. Pacing Clin Electrophysiol 2009;32:1040-9.

11. Damy T, Ghio S, Rigby AS, Hittinger L, Jacobs S, Leyva F, et al. Interplay between right ventricular function and cardiac resynchronization therapy: An analysis of the CARE-HF trial (Cardiac Resynchronization-Heart Failure). J Am Coll Cardiol 2013;61: 2153-60.

12. Sharma A, Bax JJ, Vallakati A, Goel S, Lavie CJ, Kassotis J, et al. Meta-analysis of the relation of baseline right ventricular function to response to cardiac resynchronization therapy. Am J Cardiol 2016;117:1315-21.

13. Pazhenkottil AP, Buechel RR, Herzog BA, Nkoulou RN, Valenta I, Fehlmann U, et al. Ultrafast assessment of left ventricular dyssynchrony from nuclear myocardial perfusion imaging on a new high-speed gamma camera. Eur J Nucl Med Mol Imaging 2010;37:2086-92

14. Henneman MM, Chen J, Ypenburg C, Dibbets P, Bleeker GB, Boersma E, et al. Phase analysis of gated myocardial perfusion single-photon emission computed tomography compared with tissue Doppler imaging for the assessment of left ventricular dyssynchrony. J Am Coll Cardiol 2007;49:1708-14.

15. Rajagopalan N, Suffoletto MS, Tanabe M, Miske G, Thomas NC, Simon MA, et al. Right ventricular function following cardiac resynchronization therapy. Am J Cardiol 2007;100:1434-6.

16. Donal E, Thibault H, Bergerot C, Leroux PY, Cannesson M, Thivolet $\mathrm{S}$, et al. Right ventricular pump function after cardiac resynchronization therapy: A strain imaging study. Arch Cardiovasc Dis 2008;101:475-84. 